\title{
Eclesiología y gobernación. El debate de J. Ratzinger y W. Kasper sobre la relación entre la iglesia universal y la iglesia local
}

\section{Jesús Martínez Gordo, Facultad de teología de Vitoria-Gasteiz.}

El proceso de centralización que padeció la iglesia católica durante el pontificado de Juan Pablo II fue legitimado por una teología que, nacida en la curia vaticana, defendía, entre otros puntos, la precedencia ontológica de la iglesia universal sobre la local o particular.

La Congregación para la Doctrina de la Fe y el entonces cardenal J. Ratzinger, éste último a título personal, fueron los principales valedores de un sorprendente giro eclesiológico que modificaba - con el pretexto de complementarla y corregir determinados excesos habidos en su recepción- la teología promulgada por los padres conciliares, en el Vaticano II. No es de extrañar que un posicionamiento doctrinal, institucional y personal de tanta entidad provocara muchos recelos y cautelas, porque avalaba teológicamente una forma de gobierno centralista, escasamente colegial y corresponsable; retomaba una perspectiva doctrinal unilateralmente desarrollada, en la recepción del Vaticano I (precipitadamente clausurado e inconcluso) y marginaba la eclesiología propuesta en el último concilio ecuménico.

La elección del cardenal J. Ratzinger como Benedicto XVI ha vuelto a poner de actualidad las cuestiones en juego con ocasión de este posicionamiento y el debate, posteriormente suscitado, con W. Kasper. Queda por ver si lo que, al parecer, fue interpretado por Juan Pablo II como una legítima discusión entre teólogos acaba reforzando una forma de gobierno eclesial centralista o si, por el contrario, propicia otro modo más colegial y corresponsable en este pontificado. 


\section{Iglesia local e Iglesia universal}

\subsection{La iglesia local y la iglesia universal, en el concilio Vaticano II (1962- 1965)}

Los padres conciliares no tuvieron una especial preocupación por cuidar el vocabulario. Su interés, marcadamente pastoral, determinó que las precisiones terminológicas quedaran en un segundo lugar. Esto es algo que se puede apreciar con particular claridad, cuando se analiza la cuestión de la iglesia local.

La locución ecclesia localis es empleada ocho veces: en cuatro ocasiones para designar a la diócesis, en una se refiere a la diócesis en su contexto cultural, en dos para describir un reagrupamiento de diócesis y en otra para calificar a la partoquia. Por su parte, la expresión ecclesia particularis es usada de una manera muy diversa: doce veces para designar a la diócesis, pero otras doce para referirse a una iglesia en su contexto cultural y cinco para hablar de las iglesias católicas de un rito diferente al romano'. Semejante imprecisión terminológica, en éste y en otros puntos, va a marcar los debates eclesiológicos y algunas decisiones del periodo postconciliar

Sin embargo, no todo lo referente a la iglesia local quedó en una vaporosa vaguedad, a pesar de la incuestionable ambigüedad terminológica reseñada.

Los padres conciliares dieron indicaciones más que suficientes de por dónde se decantaban al preferir, por ejemplo, la expresión portio y desestimar la de pars para referirse a la diócesis. Lo hicieron porque entendían que la iglesia local diocesana no es una parte del pueblo de Dios, sino una "porción" que comprende todas las cualidades y todas las características esenciales del todo. Esto es algo que, obviamente, no se puede decir de la "parte". El decreto conciliar Christus Dominus N. 11 es particularmente ilustrativo al respecto, cuando sostiene que "la diócesis es una porción del pueblo de Dios que se confía al obispo".

Pero los padres conciliares fueron un poco más lejos y defendieron, tratando de evitar el riesgo de comprender la diócesis como una parte de la iglesia universal, la entidad propia que presenta la iglesia local. Es sabido que en las lenguas latinas e inglesas se entiende lo particular y lo universal como opuestos, algo que choca frontalmente con lo sostenido en Lumen Gentium N. 23, donde se recuerda que las iglesias particulares están "formadas a imagen de la iglesia universal; $y$ en todas y de todas las Iglesias particulares queda integrada la sola y única Iglesia católica".

1. Cfr. L. Villemin, "Le diocèse est-il une Église locale ou une Église particulière? Quel est l'enjeu de ce vocabulaire?", en $\mathrm{H}$. Legrand y $\mathrm{C}$. Theobald, Le ministère des évêques au concile Vatican II et depuis. Hommage à Mgr. Guy Herbulot, Parls, 2001, pp. 75-93. 
Al ofrecer estas clarificaciones, facilitaron la formulación de un discurso eclesiológico en el que se enfatizaba la territorialidad como principio objetivo de agnupamiento, que está más allá de los criterios de afinidad, pertenencia social, lingüística o nacional: la iglesia había de realizarse en un lugar determinado como condición fundamental de su catolicidad.

Finalmente, es preciso reconocer que el empleo de la expresión "iglesia local" allanó el camino para el diálogo ecuménico, dado que la expresión "iglesia particular" no era, ni es, aceptada por las diferentes confesiones cristianas.

\subsection{El código de derecho canónico (1983)}

El posicionamiento conciliar reseñado empezó a quebrarse con la promulgación del Código de Derecho Canónico, en 1983. Este capital instrumento jurídico en la vida de la iglesia se decantó exclusivamente por la expresión "iglesia particular" e ignoró la de "iglesia local".

Es cierto que los redactores del nuevo código pretendían eliminar la imprecisión conciliar, pero también lo es que, de paso, invalidaban jurídicamente la argumentación teológica aportada hasta ese momento, en favor de la expresión "iglesia local".

No faltaron quienes llamaron la atención sobre lo que en realidad estaría en juego con semejante decantamiento: la relativización del criterio territorial con el fin de equiparar las llamadas diócesis o circunscripciones eclesiásticas personales con las territoriales, algo que, hasta el presente, sólo habían sido las diócesis.

Esta crítica encuentra asentamiento en el canon 368, donde la prelatura territorial, la abadía territorial, el vicariato apostólico, la prefectura apostólica y la administración apostólica, erigida de manera estable, son asimiladas a las iglesias particulares.

\subsection{El sinodo extraordinario de 1985}

El sínodo fue convocado inesperadamente, el 25 de enero de 1985, fiesta de la conversión de san Pablo, en el mismo lugar y hora en la que Juan XXIII convocó el concilio Vaticano II, veintiseis años antes (1959) ${ }^{2}$. Semejante anuncio suscitó muchos recelos, ya que fue interpretado como un intento de restauración eclesial. Siendo cierto que un sínodo - consultivo por naturaleza - no puede desplazar a un concilio (deliberativo), no era menos cierto que preocupaban las fronteras de una eventual revisión ${ }^{3}$.

2. SInodo de los obispos. Asamblea Extraordinaria (2". 1985, Roma), "El Vaticano II, don de Dios. Los documentos del Sínodo extraordinario de 1985", Madrid, 1986, p. 24.

3. Cfr. S. Madrigal, "A propósito del binomio Iglesia Universal - Iglesias particulares: status quaestionis", Diálogo ecuménico 123 (2004) 7-29; cfr. M. Alcalá, Historia del 
Estos temores aumentaron cuando, en mayo de 1985, se public6 el "Informe sobre la fe", una larga entrevista hecha al cardenal J. Ratzinger, en eI verano de - 1984, y de la cual su entrevistador (V. Messori) había publicado un adelanto en 1984. El cardenal manifestaba en esta entrevista que "si por restauración se entiende volver atrás, entonces no es posible una restauración. La Iglesia marcha adelante, hacia el cumplimiento de la historia y mira adelante hacia el Señor. Pero si por restauración se entiende la búsqueda de un nuevo equilibrio tras las exigencias de una apertura indiscriminada al mundo y tras las interpretaciones exageradamente positivas de un mundo agnóstico y ateo, pues bien, entonces sí. Semejante restauración es deseable y, por lo demás, está ya en marcha en la Iglesia. En este sentido se puede decir que se ha cerrado la primera fase, después del Vaticano II"4.

No faltaron quienes interpretaron este dictamen como un "auto de fe" al postconcilio y, en cierta medida, también al mismo concilios. A partir de este momento, empezaron a oírse a té́logos que discrepaban o compartían este diagnóstico.

Las conferencias episcopales de Estados Unidos, Gran Bretaña y Gales publicaron sus respuestas al cuestionario sinodal y las de Suiza, Holanda y España dieron a conocer amplios resúmenes. Estas conferencias episcopales apostaban por una recepción creativa y abierta del concilio. El posterior toque de atención de la curia vaticana, por la publicación de las respuestas, impidió que se conocieran los pareceres de las conferencias de Irlanda, Bélgica y Canadá.

El papa Juan Pablo II, consciente del enturbiamiento del ambiente eclesial, callo y no hizo ningún comentario sobre las afirmaciones de J. Ratzinger, mientras los preparativos del sínodo seguían su curso y, en noviembre, se procedía a su celebración.

En el aula sinodal se vio, desde el primer momento, que se daban cita tres tendencias teológicas y pastorales, claramente diferenciadas. Una primera, integrada por obispos centroeuropeos, para quienes la apelación al imaginario de la iglesia como "pueblo de Dios" se había convertido en un slogan con el cual acomodar miméticamente la iglesia a las sociedades democráticas. Otra segunda, integrada por obispos anglosajones, que reclamaba una mayor participación de los laicos, así como una potenciación de las estructuras colegiales y sinodales; y una tercera, formada por la gran mayoría de los obispos del tercer mundo, y cuya preocupación fundamental era la opción por los pobres ${ }^{6}$.

sínodo de los obispos, Madrid, 1996, pp. 271-299; J. A. Komonchak, "Introduction", Synode extraordinaire. Celebration de Vatican II, París, 1986, pp. 19-32.

4. J. Ratzinger, "Ecco perché la fede è in crisi", Jesus, noviembre (1984) 67-81.

5. Cfr. G. Zizola, La restaurazione di papa Wojryla, Roma-Bari, 1985 [Traducción española: La restauración del papa Wojtyla, Madrid, 1985, pp. 19 y ss].

6. Cfr. SInodo de los obispos. Asamblea Extraordinaria (2". 1985. Roma), "El Vaticano II, don de Dios". Los documentos del Sinodo extraordinario de 1985, pp. 43-44. 
Poco después de iniciado el sínodo, imumpió en el aula el concepto de "comunión" como una idea eclesiológica fundamental, en tomo a la cual podían articularse estas diferentes sensibilidades, desplazando -e incluso sustituyendo- a la de "pueblo de Dios"?

El primer grupo de obispos - receloso de una concepción de la iglesia como "pueblo de Dios" y partidario de acentuar su dimensión mistérica - se sentía cómodo con esta expresión, porque remitía a la comunión con Dios, por Jesucristo, en el Espíritu Santo, algo que se entrega con el bautismo, se actualiza en la palabra de Dios y, particularmente, en la eucaristía, "núcleo del misterio de la Iglesia", como posteriormente proclamará Juan Pablo II $^{\mathbf{B}}$.

La tendencia anglosajona también se sentía cómoda con este concepto, ya que integraba los puntos fundamentales de Ia Iglesia comprendida como pueblo de Dios, propiciaba la comunión ecuménica, impulsaba el principio de subsidiariedad y posibilitaba una reflexión a fondo sobre la colegialidad, las conferencias episcopales, la participación y la corresponsabilidad en la Iglesia?.

Finalmente, al recordar que "la iglesia como comunión es sacramento para la salvación del mundo", acogía - después de una consideración sobre la teología de la cruz - los intereses del tercero de los grupos, atento a la opción preferencial por los pobres, a la promoción humana, a la inculturación y al diálogo con otras religiones y con los no creyentes ${ }^{10}$.

Presentado de esta manera, parecía que el concepto "comunión" ofrecía una indudable polivalencia y recapitulaba en su seno todas las sensibilidades y doctrinas conciliares y postconciliares en juego. En contrapartida, la expresión "pueblo de Dios" pasaba - al menos, formalmente - a un segundo lugar, aunque su contenido quedara perfectamente integrado en el de "comunión".

Como es de prever, no todo fueron parabienes. Algunos padres sinodales ya apuntaron en el aula que con el concepto de "comunión" no se resolvían debidamente las cuestiones en juego, anteriores al encuentro episcopal. Concretamente, se indicó que, al ser una expresión que integraba el imaginario de "pueblo de Dios", daba alas a quienes exigían reformas estructurales, conducentes a un gobiemo más "comunional" (democrático), y a quienes pedían una mayor presencia institucional de los diferentes carismas y vocaciones en la iglesia. Y también se apuntó, desde otras posiciones antitéticas a la anterior, que al acoger

7. Cfr., ibid., pp. 50.58 y ss.

8. Juan Pablo II, Ecclesia de Eucaristia, Città del Vaticano, 2003, n 1. Cfr., ibrd., Sínodo de los obispos. Asamblea Extraordinaria (2. 1985. Roma), "El Vaticano II, don de Dios". Los documentos del Sínodo extraordinario de 1985, pp. 54 y ss. 71-78.

9. Cfr., ibld., pp. 58 y ss., 78-83.

10. Cfr., ibid., pp. 63 y ss., $84-88$. 
el indudable carácter mistérico de la iglesia, favorecía la ambigüedad y se prestaba al juego centralista y restauracionista.

En apretada síntesis: el sínodo extraordinario de 1985 no dio una respuesta solvente al temor de disgregación y dispersión que - según el diagnóstico de la curia vaticana - arrojaba la aplicación del concilio Vaticano II. Esta insatisfacción explica, en buena medida, la evolución que experimentará el mismo concepto de "comunión", en los años posteriores.

\subsection{La carta Communionis notio (1992) y clarificación oficiosa (1993)}

El 15 de junio de 1992, se publica la carta Communionis notio de la Congregación para la Doctrina de la Fe. En este documento, se asume la centralidad de la comunión, en el proyecto eclesiológico del Vaticano II, y se señala que cuando se defiende que "cada iglesia particular es un sujeto en sí mismo completo y que la iglesia universal resulta del reconocimiento recíproco de las iglesias particulares", se está proponiendo una unilateralidad eclesiológica, no sólo reductiva del concepto de iglesia universal, sino también de la misma iglesia particular. "En el fondo de semejante posicionamiento, afirma la congregación, existe una insuficiente comprensión del concepto de comunión y un incuestionable debilitamiento de la unidad de la Iglesia. La historia muestra que cuando la iglesia particular ha pretendido ser autosuficiente, debilitando su comunión con la iglesia universal y con su centro vital y visible, ha acabado cuarteándose interiormente y ha visto cómo perdía su libertad ante fuerzas que buscaban su servidumbre"".

A partir de este diagnóstico, en la carta, se proclama que la iglesia universal es, en su misterio esencial, "una realidad ontológica y cronológicamente anterior a toda iglesia particular singular"'12. Tal afirnación se efectúa en contra de quienes la entienden como "la suma de las iglesias particulares", o "la federación de iglesias particulares" o "el resultado de su comunión". Ello no impide que la Congregación para la Doctrina de la Fe sostenga, previamente a esta controvertida tesis, que entre la iglesia universal y las iglesias particulares se da una "mutua interioridad", afirmación que S. Madrigal convertirá, acertadamente, en principio hermenéutico, cuando analice el debate entre J. Ratzinger y W. Kasper sobre esta cuestión ${ }^{13}$.

11. "Lettera Communionis notio ai Vescovi della Chiesa Cattolica su alcuni aspetti della Chiesa intesa come comunione", 28 maggio, 1992, AAS 86 (1993) 838-850, $\mathrm{N}^{\mathrm{N}} 8$.

12. Communionis notio $\mathrm{N}^{\circ}$ 9: "Perciò, 'la Chiesa universale non può essere concepita come la somma delle Chiese particolari né come una federazione di Chiese particolari'. Essa non è il risultato della loro comunione, ma, nel suo essenziale mistero, è una realtà ontologicamente e temporalmente previa ad ogni singola Chiesa particolare".

13. Cfr. S. Madrigal, op. cit. 
A continuación, la Congregación para Doctrina de la Fe argumenta lo que entiende ser una mejora de la fórmula conciliar in quibus et ex quibus de Lumen Gentium, N. $23^{14}$, en los siguientes términos: "proclamando su universalidad desde su origen, la Iglesia ha dado origen a las diversas iglesias locales, como realizaciones particulares de la Iglesia una y única de Jesucristo. Naciendo en y de la Iglesia universal, es de ella y en ella como encuentran su eclesialidad".

Por consiguiente, la formula del concilio Vaticano II, "la iglesia en y a partir de las iglesias" (ecclesia in et ex ecclesiis), es inseparable de esta otra formula: las iglesias en y a partir de la iglesia (ecclesiae in et ex ecclesia)"'s, tesis ya propuesta por el cardenal J. Ratzinger, en $1990^{16}$.

El equilibrio teológico alcanzado en el texto conciliar y su claro decantamiento por una eclesiología de comunión entre la iglesia universal y la local, a partir de la precedencia de esta última, se veía sustancialmente alterado con esta carta. De ello se hicieron eco una gran cantidad de valoraciones, críticas en su mayoría ${ }^{17}$, aunque tampoco faltaron - como se verá más adelante en el caso de A. Dulles - los posicionamientos favorables.

La entidad y calidad de las críticas aportadas motivó que, el 23 de junio de 1993, se publicara en L'Osservatore Romano una nota en la cual se clarificaba oficiosamente que "la Iglesia como totalidad no se diferencia de la comunión de las Iglesias particulares, sin que ello signifique que sea una mera fusión de las mismas". Se indicaba, igualmente, que la única iglesia de Cristo no existe en abstracto, sino que se manifiesta en la historia, a la vez, como iglesia universal y como iglesia local ${ }^{18}$.

14. Lumen Gentium, N. 23: "cada uno de los obispos, por su parte, es el principio y fundamento visible de unidad en sus iglesias particulares, formadas a imagen de la iglesia universal (ad imaginem Ecclesiae universalis formatis). En ellas y a partir de ellas (in quibus et ex quibus) existe la iglesia catolica, una y única".

15. Communionis notio, N. 9: "Da essa, originata e manifestatasi universale, hanno preso origine le diverse Chiese locali, come realizzazioni particolari dell'una ed unica Chiesa di Gesù Cristo. Nascendo nella e dalla Chiesa universale, in essa e da essa hanno la loro ecclesialità. Perciò, la fórmula del Concilio Vaticano II: La Chiesa nelle e a partire dalle Chiese (Ecclesia in et ex Ecclesiis), e inseparabile da quest'altra: Le Chiese nella e a partire dalla Chiesa (Ecclesiae in et ex Ecclesia). E' evidente la natura misterica di questo rapporto tra Chiesa universale e Chiese particolari, che non è paragonabile a quello tra il tutto e le parti in qualsiasi gruppo o società puramente umana".

16. Cfr. J. Ratzinger, La iglesia. Una comunidad siempre en camino, Madrid, 1992, p. 26.

17. $C f r$. H. J. Pottmeyer, "Kirche als Commmunio. Eine Reformidee aus unterschiedlichen Perspektiven", Stimmen der Zeit 117 (1992) 579-589. Cfr. L. Örsy, "The conversion of the Churches: Condition of Unity. A Roman Catholic Perspective", America 166 (1992) 479-487.

18. Cfr. "La Iglesia como comunión. Reflexiones sobre algunos aspectos de la relación entre la Iglesia universal e Iglesias particulares", L'Osservatore Romano (ed. esp. 


\subsection{La carta apostólica Tertio millennio adveniente (1994) y el motu propio Apostolos suos (1998)}

La teología trinitaria experimentó, en los últimos decenios del siglo $\mathrm{XX}$, un desarrollo desconocido durante mucho tiempo, en la iglesia católica, y favoreció el desarrollo de una eclesiología de comunión.

Las exhortaciones post-sinodales Christifideles laici (1989) y Pastores dabo vobis (1992) se hacen eco de esta expresión. En la carta apostólica Tertio millennio adveniente de 1994, Juan Pablo II, a la vez que invitaba a aplicar plenamente el concilio Vaticano II, examinaba las grandes cuestiones conciliares necesitadas de revisión como preparación para el jubileo del año $2000^{19}$. El papa diagnosticaba a continuación la recepción conciliar y formulaba la siguiente cuestión referida a la eclesiología de comunión: “ ¿Se consolida, en la Iglesia universal y en las Iglesias particulares, la eclesiología de comunión de Lumen gentium, dando espacio a los carismas, los ministerios, las varias formas de participación del Pueblo de Dios, aunque sin admitir un democraticismo y un sociologismo que no reflejan la visión católica de la Iglesia y el auténtico espíritu del Vaticano II?"20.

El 23 de julio de 1998, Juan Pablo II publica el motu propio Apostolos suos sobre la naturaleza y los límites de la autoridad de las conferencias episcopales $^{21}$. En esta carta apostólica corrige - siguiendo la pista abierta por la carta Communionis notio - la expresión teológica de Lumen Gentium N. 23 (es "en y a partir de las iglesias particulares como existe la iglesia católica, una y única"), en favor de esta otra, la iglesia universal "es una realidad ontologica y cronológicamente previa a toda iglesia particular singular"22.

\section{El debate entre W. Kasper y J. Ratzinger (1999-2001)}

Podría parecer, a la luz de la formalización canónica y de la argumentación teológica y autoritativa aportada, que el debate eclesiológico sobre esta cuestión estaba cerrado. Nada más lejos de la realidad. El diálogo mantenido entre W. Kasper y J. Ratzinger así lo evidencia.

25.VI.1993, p. 19: "La Iglesia que se manifiesta en Pentecostés es simplemente la Iglesia de Cristo, la que en el Slmbolo confesamos con sus cuatro propiedades y que por esto sigue siendo matriz de la Iglesia universal -entendida como communio ecclesiarum - y de las Iglesias particulares, tal como se dan en el rempus Ecclesiae".

19. Juan Pablo II, Carta apost6́lica Tertio millennio adveniente, nn. 18-20.

20. lbid., N. 36.

21. Juan Pablo II, AAS 90 (1998) 457-46; DC 95 (1998) 651-653.

22. Juan Pablo II, A.S., N. 12 


\subsection{W. Kasper: el temor a un centralismo romano subyacente (1999)}

W. Kasper, entonces obispo de Rottenburg-Stuttgart, publicó, en 1999, un trabajo sobre la teología y la praxis del ministerio episcopal, en la actual situación de la iglesia ${ }^{23}$.

En el citado artículo, estudia la situación de la iglesia y aborda la relación entre la iglesia universal y las iglesias locales, llamando la atencion sobre el riesgo de un centralismo romano, latente en el documento de la congregación de 1992. En particular, porque tiende a identificar la realidad teológica "iglesia universal" con la curia romana y con una forma de gobiemo centralizadora: "si esto sucede, entonces la carta de la Congregación para la Doctrina de la Fe no se puede entender como una contribución al esclarecimiento de la eclesiología de comunión; se debe comprender como su abandono y como el intento de una restauración del centralismo romano"24.

Entiende que la comunidad originaria de Jerusalén fue, de hecho, iglesia universal e iglesia local al mismo tiempo y señala que, muy probablemente ya desde el inicio, existían más comunidades, además de la de Jerusalén, también la de Galilea.

\subsection{J. Ratzinger: la precedencia ontológica de la iglesia universal (2000)}

La respuesta de J. Ratzinger llega en el congreso internacional sobre la aplicación del concilio Vaticano II, organizado por el comité para el gran jubileo del año 2000 , celebrado en la ciudad del Vaticano del 24 al 26 de febrero.

El entonces cardenal J. Ratzinger presenta la eclesiología de Lumen Gentium, analizando las potencialidades y limitaciones de la iglesia como "pueblo de Dios" y del concepto integrador de "comunión", propuesto en el sínodo extraordinario de $1985^{25}$.

Reconoce la existencia de desequilibrios que deben corregirse como consecuencia de un centralismo romano excesivo, defiende el texto de la Congregación de 1992, en su intento por superar el "igualitarismo" y el reparto de competencias, en el seno de la iglesia ${ }^{26}$, critica a los teólogos que sienten el deber de valorar negativamente los documentos de la Congregación para la Doctrina de la Fe con

23. Cfr. W. Kasper, "Zur Theologie und Praxis des bischöflichen Amtes", en W. SchreerG. Steins (eds.), Auf neue Art Kirche sein (FS Bischof Dr. Josef Homeyer), München, 1999, pp. 32-48.

24. Cfr. W. Kasper, ibid.

25. Cfr. J. Ratzinger, "L'ecclesiologia della costituzione Lumen Gentium", en R. Fisichella (ed), II Concilio Vaticano II. Recezione e attualità alla luce del Giubileo, Cinisello Balsamo, 2000, pp. 66-81.

26. Cfr. J. Ratzinger, ibid., "Mientras el Señor va hacia su pasión; mientras la iglesia, y en ella Él mismo, sufre, nosotros nos dedicamos a discutir sobre nuestro tema preferi- 
el fin de "cuidar de su celebridad" personal, estudia la relación entre la iglesia universal e iglesias locales, defendiendo la precedencia de la primera ${ }^{27}$, argumenta dicha antecedencia a partir de los sacramentos (bautismo y eucaristía, particularmente $)^{28}$ y muestra su desacuerdo con quienes afirman la simultaneidad de la iglesia universal y de las iglesias particulares.

$\mathrm{Al}$ abordar algunos de estos puntos, había que pasar por una referencia directa y explícita a W. Kasper, presente en el encuentro.

\subsection{W. Kasper: la perspectiva de la "mutua inclusión", la "simultaneidad", la "mutua interioridad" o la perijóresis (2000)}

La réplica de W. Kasper llegó en diciembre del año 2000, en un artículo titulado: “Acerca de la Iglesia. Discusión amigable con la crítica del cardenal J. Ratzinger"29.

El todavía obispo de Rottenburg-Stuttgart abunda en los problemas prácticos que tiene que abordar como pastor de una iglesia que vive una creciente separación entre las normas de la iglesia universal y la praxis de un lugar. "Como obispo de una vasta diócesis, he podido observar cómo ha ido surgiendo una brecha, que progresivamente se ha ido patentizando, entre las normas promulgadas en Roma por la iglesia universal y las necesidades y prácticas de nuestra iglesia particular. Gran parte de nuestro pueblo, incluso sacerdotes, no podía comprender la razón que estaba detrás de las reglamentaciones provenientes del centro; y tendía por ello a ignorarlas" 30 . Este es un comportamiento que afecta tanto a cuestiones éticas como disciplinares, sacramentales y ecuménicas.

Ante esta situación, el obispo se siente impelido en dos direcciones que, a veces, son excluyentes: una que le recuerda la solidaridad con el colegio episcopal y con el papa y su cuidado de la unidad, y otra que le urge a atender las

do, sobre nuestros derechos de precedencia. Y si Cristo viniera a nosotros y nos preguntara de qué estábamos hablando, sin duda nos sonrojarlamos y callaríamos".

27. Cfr., ibíd., "La prioridad ontológica de la Iglesia universal, de la única Iglesia y del único cuerpo, de la única Esposa, con respecto a las realizaciones empíricas concretas en cada una de las Iglesias particulares, me parece tan evidente, que me resulta difícil comprender las objeciones planteadas" [...]. "La resistencia contra las afirmaciones de la precedencia de la Iglesia universal con respecto a las Iglesias particulares es teológicamente difícil de comprender o, incluso, incomprensible".

28. Cfr., ibid. "En el bautismo la Iglesia universal precede continuamente a la iglesia local y la constituye" [...]. "La eucaristua no nace de la iglesia local y no termina en ella".

29. Cfr. W. Kasper, "Das Verhältnis von Universalkirche und Ortskirche. Freundschaftliche Auseinandersetzung mit der Kritik von Joseph Kardinal Ratzinger", Stimmen der Zeit 218 (2000) 793-804.

30. W. Kasper, ibld. 
expectativas y preguntas de la iglesia local que preside. El obispo puede tener la impresión de estar sorteando permanentemente el doble filo de la desobediencia (a los ojos de Roma) y de la imposición (a los ojos de sus fieles), algo que, además de inútil, es contraproducente. Para salvar esta situación, es preciso permitir que los obispos puedan tomar responsablemente las decisiones que consideren oportunas, en la aplicación de leyes disciplinares, dejando a salvo las materias inmutables de fe y moral.

Esta manera de gobernar se funda en la teología de la iglesia particular y en la función del obispo. "La iglesia particular no es - prosigue W. Kasper- ni una provincia ni un departamento de la iglesia universal; es la iglesia en un lugar determinado. El obispo local no es el delegado del papa, sino alguien enviado por Jesucristo, quien le confíó una responsabilidad personal. Mediante su consagración sacramental, recibe la plenitud del poder que necesita para gobemar su diócesis. Esta es la enseñanza del concilio Vaticano II"31. Si se hubiera comprendido adecuadamente la misión del obispo, se habría activado un proceso descentralizador en el gobiemo de la iglesia. Sin embargo, se ha impulsado la tendencia centralizadora, perdiéndose el equilibrio adecuado entre iglesia universal e iglesias locales. Este es un diagnóstico que comparten, entre otros, el arzobispo John Quinn y los cardenales Carlo Maria Martini y Franz Koenig.

J. Ratzinger - apunta W. Kasper- se ha limitado a enfocar la cuestión desde un punto de vista teórico y abstracto, descuidando las situaciones y experiencias concretas ${ }^{32}$. Además, le ha acusado de proponer una teología eclesial carente de profundidad teológica y que reduce la esencia eclesial a comunidades separadas, empíricamente desarrolladas. Todo esto lleva a Kasper a dar una cuidadosa explicación de su posición, desde el punto de vista histórico para pasar a exponer los puntos de acuerdo y los núcleos en los cuales quedan centrados los desacuerdos.

\subsubsection{Argumentación histórica}

Cuando se deja que los textos escriturísticos, patrísticos y conciliares hablen por sí mismos, entonces es posible percatarse de que desde los primeros tiempos funcionó un sistema de comunión, a partir de los obispos de las diferentes iglesias. En esta concepción y praxis de la comunión quedaban descartados tanto el unilateralismo al cual podía ser proclive una eclesiología local y localista como la eclesiología unidimensional, a la cual era propensa la eclesiología vivida en clave universalista.

31. Ibid.

32. Cfr., ibld., "La relación entre la Iglesia universal y las Iglesias particulares no puede explicarse en abstracto por la vía de deducciones teóricas, porque la Iglesia es una realidad histórica concreta. Bajo la guía del Espíritu se despliega en la historia; por la misma teología debemos remitimos, pues, a la historia". 
Nadie discute - apunta W. Kasper - que el segundo milenio estuvo presidido por una fuerte afirmación del primado, ni que tal afirmación estuvo marcada por su confrontación con las fuerzas centrífugas del conciliarismo, de la reforma, del Estado absolutista modemo, del galicanismo y del josefinismo ${ }^{33}$. Es evidente, además, que semejante confrontación desembocó en la doctrina del primado de jurisdicción del papado.

Sin embargo, la gran aportación del Vaticano II consistió en equilibrar la tradición eclesial más antigua con el concepto de primado, que se consolidó en el Vaticano I. Este equilibrio descansaba -y sigue descansando- en tres pilares: la doctrina de la iglesia local, la sacramentalidad de la consagración episcopal y la colegialidad del episcopado. Por eso, la tesis sobre el primado ontológico de la iglesia universal sobre las iglesias locales de la carta Communionis notio de 1992 es una ruptura de dicho equilibrio y una invalidación del sínodo extraordinario de 1985.

\subsubsection{Argumentación sistemática}

J. Ratzinger, recuerda W. Kasper, fundamenta su posición en la tesis de la preexistencia de la iglesia. Es cierto - reconoce- que existen textos en los que se habla del mysterion escondido y revelado en la iglesia y a través de la iglesia (cfr. Ef $1,3-14 ; 3,3-12$; Col 1, 26 y ss). No se puede ignorar la idea de una iglesia preexistente. Es algo correcto para una comprensión teológica de la iglesia.

De esta preexistencia no se deriva, sin embargo, ninguna consecuencia sobre la relación entre la iglesia universal y las iglesias locales en el sentido de una prioridad de la iglesia universal. La preexistencia de la iglesia puede fundar también la tesis de la simultaneidad (perijóresis) entre la iglesia universal y las iglesias particulares. Las reflexiones del cardenal Ratzinger no han logrado probar la prioridad de la iglesia universal sobre las iglesias locales. Dios no ama las abstracciones vacías, sino a las personas concretas, de carne y hueso.

\subsubsection{Los puntos de acuerdo}

El desacuerdo sobre esta cuestión no puede hacer olvidar, sin embargo, los puntos que comparten ambos y que W. Kasper se encarga de explicitar: (a) La única iglesia de Jesucristo existe en el presente. No es una "suma de fragmentos de la única iglesia", sino que "subsiste en" la iglesia católica romana; (b) La única iglesia de Jesucristo existe "en y a partir de" las iglesias-locales. Existe, por tanto, en cada iglesia local. Por eso, no puede haber iglesia local aislada sino sólo en la comunión con las demás iglesias locales. La unidad de la iglesia

33. Doctrina y praxis que defiende que sean las autoridades civiles las que digan a los catolicos lo que hay que creer y hacer y que trata como asunto de Estado todo cuanto de alguna manera guarde relación con la organización externa de la Iglesia prohibien- 
universal es unidad en comunión. Ello quiere decir que las iglesias locales y la iglesia universal se incluyen mutuamente cada una en las otras; (c) De la misma manera que las iglesias locales no son meras extensiones o provincias de la iglesia universal, la iglesia universal no es la suma ni la federación de las iglesias locales. Su estructura constitucional está configurada a imagen de la Trinidad, es decir, de un Dios en tres personas, de tal manera que la unidad de la iglesia no es uniformidad, ni excluye la diversidad.

\subsubsection{Un asunto libremente disputado}

El debate gira, apunta W. Kasper, sobre perspectivas teológicas claramente diferencias: la del cardenal Ratzinger, defensora de una concepción universalista del primado y la mía, para la cual lo universal existe en una realidad concreta. Se repite el diálogo de perspectivas que, en la edad media, sostuvieron santo Tomás y san Buenaventura. Si en ese tiempo se admitía semejante diversidad en la compresión de la autoridad universal del papa, ¿por qué, pregunta el obispo de Rottenburg - Stuttgart, no puede ser posible hoy?

Finalmente, a W. Kasper no se le escapa la fuerza ecuménica de la expresión "comunión" como principio regulador de una unidad no uniformadora e impulsora de una iglesia reconciliada con la diversidad, es decir, de una iglesia atenta a la unidad, respetando la diversidad y cuidosa de la pluralidad en la unidad. Una iglesia en la que el papado tendría como misión garantizar y favorecer ese equilibrio.

\subsection{El cierre del debate (2001)}

$\mathrm{Al}$ año siguiente, J. Ratzinger es invitado por la revista America a exponer su parecer sobre la postura de W. Kasper, recientemente nombrado cardenal ${ }^{34}$.

J. Ratzinger manifiesta su satisfacción por los puntos de acuerdo alcanzados a lo largo de este debate y que W. Kasper se ha encargado de explicitar. Le agrada, así mismo, que el recientemente nombrado cardenal haya superado la identificación que establecía en 1999 entre el papa y la curia vaticana con la iglesia universal, así como su temor a una restauración del centralismo romano.

do a sus obispos toda comunicación con Roma. Está muy vinculado con el febronianismo, doctrina según la cual los obispos son los únicos jueces de la fe por derecho divino y están habilitados para deponer - con la ayuda del poder civil- al papa si se sale fuera de sus atribuciones y competencias, al ser un primus inter pares y la parte ejecutiva de los cánones conciliares. Consecuentemente, ninguna ley pontificia tiene valor si no es aprobada antes por los obispos.

34. Cfr. J. Ratzinger, "A Response to Walter Kasper: The Local Church and the Universal Church", America 185 (November 19, 2001) 7-11. Con anterioridad, la revista había publicado - traducida al inglés - la réplica de W. Kasper del año 2000: "Acerca de la lglesia. Discusión amigable con la crítica del cardenal J. Ratzinger”. 
Entrando en la cuestión teológica de fondo, manifiesta no tener dificultades para aceptar la interpretación que propone W. Kasper. Ello no le impide reconocer, a continuación, lo sorprendente que le resulta que su tesis sobre la iglesia universal haya levantado tantos recelos en téblogos de la solvencia del entonces obispo de Rottenburg-Stuttgart ${ }^{35}$. Y más, habida cuenta de que la iglesia de Roma, siendo una iglesia local, es también una iglesia con una responsabilidad singular por la universalidad ${ }^{36}$.

A continuación apunta - algo totalmente nuevo en el debate habido hasta entonces - que la primacía de la iglesia universal no es de naturaleza ontológica sino teleológica. Y lo hace con la intención de encajar la idea de una iglesia preexistente con el fin de la creación y de la historia de la salvación y así desactivar el malentendido de una supuesta restauración del centralismo vaticano.

Esta nueva consideración, sin embargo, no le aparta de su tesis sobre la precedencia en la intención salvífica de Dios de la iglesia una con respecto a la realización empírica en las iglesias particulares ${ }^{3}$. Por eso, el problema no lo sitúa en las diferentes perspectivas teológicas en juego (la platónica o la aristotélica como propone W. Kasper), sino en la noción de historia de la salvación en la Biblia.

En su respuesta, W. Kasper se alegrará de la superación de los malentendidos, así como por el avance positivo, experimentado a lo largo del debate, y preguntará a J. Ratzinger si la preexistencia de la iglesia en la voluntad salvífica de Dios no vale al mismo tiempo para la iglesia universal y para las iglesias locales. Se reafirma, como se puede apreciar, que la clave hermenéutica de este debate se encuentra en la apuesta por la prioridad de la iglesia universal sobre la local (en el caso de J. Ratzinger) o de la "mutua interioridad", "mutua inclusión", "simultaneidad" o perijóresis entre ambas (como propone él mismo) ${ }^{38}$.

\section{Dos valoraciones críticas del debate}

La declaración de la Congregación para la Doctrina de la Fe sobre el concepto de "comunión" y el debate entre ambos cardenales, formalmente cerrado el año 2001 , propician, como es de prever, posturas a favor y en contra. Basten como muestras dos botones.

35. Cfr., ibfd., "I can certainly accept this formula; it is valid for the church as it lives in hislory".

36. Cfr., ibid., "The Church of Rome is a local church and not the universal church -a local church with a peculiar, universal responsibility, but still a local church".

37. Cfr., ibid., "In baptism the universal church continually precedes and creates the local church".

38. Cfr. W. Kasper, "From the President of the Council for Promoting Christian Unity", America 185 (November 26, 200I) 28-29. 


\subsection{Jürgen Werbick: una infeliz formulación}

Hablar de precedencia ontológica y cronológica de la iglesia universal sobre la local es para J. Werbick una "infeliz formulación", que lleva a abandonar el equilibrio alcanzado por los padres conciliares, entre las dimensiones universales y locales de la iglesia. Pero la formulación propuesta por la Congregación para la Doctrina de la $\mathrm{Fe}$ - defiende el dogmático de Münster - no sólo entra en contradicción con la doctrina del concilio Vaticano II, sino que subraya el componente jerárquico de la comunión y descuida - algo que desde el punto de vista eclesiológico ha de evaluarse positivamente - su irrenunciable poliformidad y variedad ${ }^{39}$.

Es cierto que la declaración no invalida de forma explícita el equilibrio entre la iglesia universal y la local, pero concibe de manera tan estrecha la "íntima" dependencia de las iglesias locales de su vértice jerárquico que casi no queda espacio para la legítima autonomía y diversidad en la conmunio de las iglesias locales. Es así como la declaración se convierte en un intento de legitimación teológica del actual régimen eclesiástico, marcadamente centralista, algo que no había sucedido en toda la historia postconciliar de la iglesia.

No hay que sorprenderse, prosigue $\mathrm{J}$. Werbick, de que en el documento no haya referencia alguna al peligro opuesto, es decir, a que el centralismo puede vaciar la responsabilidad por la comunión propia de las iglesias locales, para acabar haciendo de la iglesia una mega-institución burocratizada y lejana de las situaciones concretas, en las cuales se pone a prueba la fe. Como tampoco hay que sorprenderse de que no haya referencia alguna al deseable equilibrio entre la unidad y la autonomía o sobre un ministerio petrino, que favorezca la unidad y la comunión sinodal. Da la impresión de sostener implícitamente que la participación contradice la "naturaleza" y el "misterio" de la iglesia.

Estos silencios son consecuencia normal de una concepción de la comunión y de la colegialidad, pensadas casi exclusivamente desde la perspectiva de la unidad. Y como es de prever, acaban reconducidas, al final, al ministerio de promover la unidad del sucesor de Pedro. Siendo ésta la perspectiva favorecida, no hay que extrañarse de que el significado eclesiológico positivo de la diversidad y de la pluralidad de las iglesias y de los sujetos particulares - algo que se encuentra en la entraña misma de la communio eclesial - no sea explicitada, en ninguna ocasión.

Para los autores de la declaración, communio quiere decir, concluye J. Werbick, un rebaño reunido por los pastores, bajo el supremo pastor, o, por decirlo

39. J. Werbick, Kirche, Ein ekklesiologischer Ennwurf firr Studium und Praxis, Freiburg im Breisgau, 1994 [Traducción al italiano: La chiesa. Un progetto eclesiológico per lo Studio e per la prassi, Brescia, 1998, pp. 381 y ss]. 
de manera teológicamente más elaborada, una comunidad cultual eucarística a la cual se garantiza la participación en la santidad, por la presencia de presbíteros.

\subsection{A. Dulles: la consistencia y oportunidad de la posición adoptada por J. Ratzinger}

El año 2001, el cardenal Avery Dulles se siente obligado a intervenir en el debate entre W. Kasper y J. Ratzinger con un artículo que publica en la revista Inside the Vatican ${ }^{40}$. Y lo hace para indicar, en primer lugar, que la revista América y su director, Thomas Reese, han exagerado la supuesta "polémica" sobre la iglesia entre ambos cardenales. A. Dulles recuerda que el semanario America publicó, en abril de 2001, la traducción de un artículo de W. Kasper, impreso en diciembre del 2000, por la revista alemana Stimmen der Zeit, es decir, antes de que fuera nombrado cardenal y presidente del pontificio Consejo para la Unidad de los Cristianos.

Al presentarlo como una disputa entre cardenales ("sobre la iglesia universal: una amistosa respuesta del cardenal Walter Kasper al cardenal Joseph Ratzinger"), sin indicar que W. Kasper publicó dicho artículo siendo todavía obispo de Rottenburg-Stuttgart, se presta a engaño, puesto que da la impresión de que lo escribió siendo cardenal y presidente del pontificio Consejo para la Unidad de los Cristianos. La revista America, observa A. Dulles, no aclara este capital extremo, permitiendo interpretar que estamos ante un debate entre dos responsables de diferentes dicasterios romanos: "si el artículo hubiera sido escrito por Kasper en su actual cargo, eso habría sugerido que la iglesia no tiene una, sino dos Congregaciones para la Doctrina de la Fe y que ambas estaban virtualmente en guerra".

A continuación, el cardenal A. Dulles manifiesta desconocer si W. Kasper aprobó la publicación de su artículo en inglés o si revisó personalmente la traducción, porque los términos empleados en la traducción inglesa son mucho más agresivos y tajantes que los que se pueden leer en el original alemán. Y cita varios ejemplos: la versión inglesa habla de "dura resistencia" (adamant refusal) de la Santa Sede para aceptar algunas propuestas, o de las "reglas altamente restrictivas" (highly restrictive rules) de Roma, o de las supuestas expectativas de Roma de que los obispos "fuercen rudamente la aplicación de normas generales". Estos términos acusatorios no se encuentran, apunta A. Dulles, en el texto original alemán.

Aclarados estos extremos, el cardenal Dulles sintetiza las posiciones de $\mathrm{W}$. Kasper y J. Ratzinger, al hilo de la declaración de la Congregación para Doctrina de la Fe sobre el concepto "comunión" (1992). Y lo hace intentado mostrar

40. Cfr. A Dulles, "Ratzinger and Kasper on the Universal Church", Inside the Vatican 100 , junio 2001. Puede verse un amplio extracto del texto en http:/www.cardinalrating.com/cardinal_181_article_226.htm 
que, pese a las indiscutibles diferencias, existen más puntos en común de lo que se supone y de lo que la revista America da a entender con su manera de presentar el debate.

Esta defensa de un supuesto acuerdo entre ambos no obsta para que A. Dulles muestre claramente su preferencia por la doctrina sobre la precedencia ontológica y cronológica de la iglesia universal sobre la local, tesis que defiende el cardenal Ratzinger. Coincide con él en que la iglesia universal no es el simple resultado de la expansión de una comunidad local inicial, sino la "Jerusalén de arriba" y que Pablo describe como "nuestra madre" $(\mathrm{Gal} \mathrm{4,26).}$

Por su parte, W. Kasper, indica el cardenal estadounidense, no niega la preexistencia de la iglesia. Simplemente, sostiene que dicha preexistencia no es propia sólo de la iglesia universal sino también de las iglesias históricas concretas, iglesias que hunden, igualmente, sus raíces en el misterio etemo de Dios. Ahora bien, A. Dulles abunda en la crítica, al argumentar diciendo que no demuestra que la nueva Jerusalén, proclamada por el Nuevo Testamento y por las fuentes patrísticas, consista en una multitud de iglesias.

$\mathrm{Y}$ si nos atenemos al plano histórico, en el que preferentemente se coloca $\mathrm{W}$. Kasper, también es preciso reconocer - apunta el cardenal estadounidense - la prioridad de la iglesia universal sobre la local. Es incuestionable que Cristo ha congregado la comunidad de los discípulos y ha preparado a los apóstoles para la misión. Las iglesias particulares han aparecido sólo cuando la iglesia se ha dispersado y ha sido necesario constituir asambleas locales con sus propios responsables jerárquicos.

W. Kasper afirma, en un momento del debate - prosigue A. Dulles-, que Ratzinger adopta una perspectiva platónica, ya que parte de conceptos universales, en vez de entender que dichos conceptos universales no son sino una simple abstracción de la realidad concreta que es, por definición, particular. A. Dulles reconoce que $\mathbf{J}$. Ratzinger presenta una cierta afinidad con el platonismo cristiano, lo que no le impide fundamentar su posición en la escritura y en la tradición y no en la filosofía platónica. Por eso, afirma de forma taxativa que la iglesia universal, animada por el Espíritu Santo, existe aquí en la tierra, en la historia. Y atribuyendo a Ratzinger la clarificación oficiosa del año 1993, apunta que en este texto insiste en el hecho de que no hay nada más concreto que la reunión de 120 discípulos, en Jerusalén.

En otro momento de su aportación, indica A. Dulles, W. Kasper afirma, cargado de razones, que según el Vaticano II, el obispo recibe la tarea de gobernar (munus regendi) de forma directa de Cristo, por medio del sacramento del orden (Lumen Gentium N. 21), pero olvida decir que no puede gobernar una diócesis si no ha sido canónicamente nombrado por el papa y si no conserva la comunión jerárquica con el colegio de los obispos y con su jefe, el obispo de 
Roma (Lumen Gentium N. 24). El obispo sólo puede ejercer su cargo de enseñar y gobernar en comunión con el Pontífice Romano (Lumen Gentium n. 22).

La aplicación de este principio teológico quiere decir que, por ejemplo, ningún problema grave en una iglesia particular puede justificar la aplicación de normas excepcionales, diferentes de las establecidas para la iglesia universal. $Y$ argumenta dicha postura indicando que si se tratara de problemas en realidad graves, éstos, necesariamente, atañerían a la iglesia universal, como así sucede con la admisión a la eucaristía de cristianos no católicos o de católicos divorciados y vueltos a casar. No se pueden ensayar soluciones locales a cuestiones que no son exclusivas de la diócesis que presidía, en su día, el ahora cardenal Kasper. Los problemas en Rottenburg-Stuttgart no difieren de forma significativa de los de Munich, Johannesburg o Nueva York. Cualquier política permitida en Rottenburg-Stuttgart no sólo concierne a esa dí́cesis, sino que de modo inevitable tiene repercusiones en el resto del mundo católico.

W. Kasper, concluye el cardenal estadounidense, no es ningún extremista partidario de una iglesia concebida como una federación de iglesias locales o nacionales. La experiencia del galicanismo y de movimientos análogos le ha enseñado a recelar de semejante modelo de iglesia. Sin embargo, tendría que reconocer que en los tiempos actuales, marcados por una creciente globalización y múltiple inculturación, es capital tener un primado que cuide y vele por la unidad de todas las iglesias particulares, en aquello que es esencial, tanto en la fe y moralidad como en el culto.

\section{Algunas conclusiones}

El debate reseñado se presta, cuando menos, a dos tipos de consideraciones conclusivas: una más teológica y otra más práctica.

\subsection{Las perspectivas teológicas en juego}

Es cierto que en este debate subsisten acentos que acaban configurando perspectivas claramente diferenciadas, más allá del nombre que se les quiera adjudicar.

Es incuestionable que $\mathbf{J}$. Ratzinger subraya la dimensión trinitaria del concepto de communio para salir al paso de una reducción sociológica y de una "progresiva horizontalización" del mismo y de la iglesia. Para quien fuera prefecto de la Congregación para la Doctrina de la Fe, el significado trinitario del término communio se encuentra en $1 \mathrm{Jn}$ 1, 3: "lo que hemos visto y oído, se los anunciamos, para que también ustedes estén en comunión con nosotros. Y nosotros estamos en comunión con el Padre y con su Hijo Jesucristo".

La iglesia, en particular la jerárquica, media y comunica la comunión de las personas divinas. Gracias a los sucesores de los apostoles, la iglesia es, entre los hombres, instrumento de la comunión con Dios en Cristo, en la fuerza del Espí- 
ritu (cfr. Lumen Gentium N. 1). Esta comunión viene celebrada en la eucaristía y es, a la vez, comunión de diferentes servicios, tareas y ministerios. La iglesia, así entendida, es, según J. Ratzinger, una realidad universal, que preexiste y precede incluso ontológica y temporalmente a las iglesias locales.

Cuando estos puntos no son debidamente tenidos en cuenta, es frecuente encontrarse con posiciones que defienden, ya sea por vía práctica o teológica, que la iglesia católica es la suma de las igleșias diocesanas o su federación, dando a entender que las iglesias locales pudieran existir con independencia del hecho de ser en conjunto.

W. Kasper, por su parte, habla de la simultaneidad o perijóresis entre la iglesia universal y la local. Entiende que subrayar la iglesia local no provoca un reduccionismo sociológico, porque su unidad no queda constituida de manera autónoma con las otras, sino que nace como iglesia, unida a priori con ellas. Asentado esto, no tiene dificultad alguna en aceptar una prioridad interna de la unidad eclesial. En la eternidad de Dios preexistináa la idea de la iglesia universal, junto a la de las iglesias locales.

J. Ratzinger está cargado de razones cuando recuerda que cada obispo es sólo obispo de una iglesia local, en la medida en que se encuentra en comunión jerárquica, es decir, en unión con el colegio episcopal y con el sucesor de Pedro. Hans Urs von Balthasar ya recordó en su día, que el sentido del término communio indica un a priori con relación a las iniciativas de individuo. También es preciso reconocer, sin embargo, que su posición presenta dificultades de orden conceptual y epistemológico.

Desde el punto de vista conceptual, define a la diócesis como una parte de un todo (la iglesia universal). En esto concuerda con la opción del CIC de 1983 (a favor de "particular" en vez de "local"), pero no con el Vaticano II (Christus Dominus N. 11). El Vaticano II no impone la expresión "iglesia particular". Es algo que deja libre, manifestando una cierta preferencia, como se ha indicado, por la expresión "iglesia local".

Desde el punto de vista epistemológico, resulta difficil concebir una iglesia que sea anterior a sus miembros, más en concreto, a la fe y a los sacramentos que la hacen existir. Esto refleja una concepción platónica difícilmente compatible con Lumen Gentium N. $8^{41}$ y que no tiene nada que ver con la preexistencia de la iglesia en el designio de Dios.

41. Cfr. Lumen Gentium N. 8: "La iglesia terrestre y la iglesia enriquecida con los bienes celestiales no deben ser consideradas como dos cosas distintas, sino que más bien forman una realidad compleja que está integrada de un elemento humano y otro divino. Por eso se la compara, por una notable analogía, al misterio del Verbo encarnado". 
Parece más correcto concebir la iglesia entera no como el resultado de la comunión entre las iglesias, sino como su comunión en una "inclusión mutua", según una fórmula que ya emplé Juan Pablo П, en el año $1985^{42}$. Una iglesia local es plenamente iglesia de Dios, porque la preside un obispo, a pesar de que no sea toda la iglesia. La presidencia episcopal expresa la comunión entre todas las iglesias, ya que todos los obispos en conjunto y colegialmente son responsables de la iglesia de Dios.

\subsection{Las formas de gobjerno en juego}

Pero el debate reseñado no se cin̄e sólo a la mera discusión entre diferentes y legítimas perspectivas eclesiológicas, sino que trasciende, sobre todo, a las diferentes formas de entender el gobierno eclesial (centralizado o colegial y corresponsable).

Hay que agradecer a A. Dulles haber mostrado, particularmente en sus consideraciones hacia el final del artículo, que lo que está en juego en este debate no son sólo dos maneras diferentes de entender la iglesia, sino también, y sobre todo, de gobernarla: una más centralista y centralizadora, como consecuencia de la globalización del mundo y de la importancia de mantener la unidad, y otra, más partidaria de la pluriformidad $y$, por tanto, de una cierta adaptación e inculturación que, sin tocar para nada lo que es fundamental, favorezca la libertad y creatividad ante lo que está necesitado de una prudente adaptación.

La forma de gobernar que propone A. Dulles - al hilo de su adhesión a la tesis de J. Ratzinger - está presidida por la fime voluntad de mantener la unidad de la iglesia, en un mundo convertido en aldea global. Consecuentemente, es una forma de gobiemo vigilante de todo lo que sea magisterio discordante o simple reivindicación de lo particular. El papa es concebido como una especie de obispo de toda la tierra, en un mundo que se ha globalizado. En consecuencia, cualquier propuesta de inculturación encuentra dificultades para eludir la sospecha de trabajar en el sentido de una ruptura de la unidad.

Un diagnóstico de este estilo explica, en buena medida, la inquebrantable adhesión a la propuesta eclesiológica defendida por J. Ratzinger y a decisiones tales como que, por ejemplo, se prohiba que los sínodos se pronuncien -incluso bajo la forma de un simple "voto que transmitir a la Santa Sede" - sobre cualquier tema que implique posiciones no concordantes con la doctrina perenne de la iglesia o del magisterio pontificio o que afecten a materias disciplinares, reservadas a la autoridad eclesiástica superior ${ }^{3}$. Esto quiere decir que las iglesias

42. AAS 77 (1985) 506.

43. Cfr. Congregación para los Obispos. Congregación para la Evangelización de los Pueblos, Instructio de Synodis diocesanis agendas, N IV, 4. AAS 89 (1997) 706-727: "Teniendo presente el vínculo que une la Iglesia particular y su Pastor con la Iglesia 
locales no pueden proponer un testimonio de fe mínimamente diferente en su expresión del magisterio pontificio. La misma regla vale en el marco de los sínodos con el papa, comprendidos los sínodos continentales ${ }^{44}$.

Buscándolo o no, nos encontramos, de facto, con la eclesiología vigente la víspera del concilio, en la cual la jerarquía sofoca la comunión de las iglesias locales - como sujetos que son de derecho e iniciativa-, en el seno de la comunión de la iglesia entera. La Santa Sede, si no se reserva el monopolio de la interpretación de la fe cristiana, en todas las culturas del mundo entero, ejerce, cuando menos, un control estricto y actúa como si fuera la guía inmediata, conservando -y si es el caso, reclamando- la iniciativa, en este campo. Parecen cargados de razones quienes tienen dificultades para ver en estas determinaciones una realización de los deseos de los padres conciliares.

La forma de gobernar que se desprende y late en la propuesta de W. Kasper es bien diferente. Apuesta claramente por la colegialidad y la sinodalidad y por buscar mecanismos, a través de los cuales pueda ser canalizada.

Quizá uno de los ejemplos más claros es el que se dio con ocasión de las elecciones presidenciales de Estados Unidos, el año 2004. La curia romana se pronunció, en su día, negando la comunión a los políticos católicos que defendieran públicamente el aborto (el caso del candidato J. F. Kerry). Los obispos estadounidenses reivindicaron la competencia de cada uno de ellos a la hora evaluar y aplicar semejante medida, que nadie discutía, en sus respectivas diócesis. Esta postura llevó a que el semanario italiano $L^{\prime}$ Espresso sostuviera que era contraria a los principios generales, formulados por el cardenal J. Ratzinger, en Dignitò a ricevere la santa comunione ${ }^{45}$. El equívoco tuvo que ser clarificado, finalmente. con la publicación de una carta del entonces prefecto de la Congregación para la Doctrina de la Fe al cardenal McCarrick, en la cual le comunicaba que el criterio adoptado por los obispos estadounidenses estaba "en grandísima armonía con los principios generales enviados con anterioridad por la congregación"46.

universal y el Romano Pontífice, el Obispo tiene el deber de excluir de la discusión tesis o proposiciones - planteadas quizá con la pretensión de transmitir a la Santa Sede 'votos' al respecto- que sean discordantes de la perenne doctrina de la Iglesia o del Magisterio Pontificio o referentes a materias disciplinarias reservadas a la autoridad suprema o a otra autoridad eclesiástica".

44. Cfr. J. Martínez Gordo, "El gobiemo de la Iglesia: sintomas de un malestar", Surge 626 (2004) 443-465; Razón y fe, 1279 (2005) 411-430, donde analizo esta forma de gobierno con más detenimiento

45. Cfr. S. Magister, "Caso Kerry. Cì̀ che Ratzinger voleva dai vescovi americani", L'Espresso, 3 de julio de 2004.

46. J. Ratzinger, "Lettera del Card. Ratzinger al Card. McCarrick", Il Regno, documenti 15 (2004) 486. Cfr., ibld., Vescovi, USA, "I cattolici nella vila politica", Il Regno, documenti 15 (2004) 487. Card. Th. McCarrick, "I cattoloci nella vita politica", II Regno, documenti 15 (2004) 483-486. 
Es probable que el momento más logrado de gobiemo colegial y corresponsable haya sido el vivido durante los sínodos que se celebraron en el tiempo inmediatamente posterior a la finalización del concilio Vaticano II. Aunque estaba claro que los sínodos no tenían valor deliberativo, sin embargo, fue una forma de colegialidad muy privilegiada por Pablo VI, hasta el punto que el papa llegó a asumir como propios algunos textos aprobados, en dichos sínodos.

También es cierto que esta forma de gobernar desencadenó un sin fin de recelos, en la curia vaticana, no sólo por el protagonismo que concedía a determinados personajes e iglesia locales, sino porque entendía que en ella se incubaban fuerzas centrífugas, algo que podía llevar al cisma.

El temor a un posible cisma en la iglesia católica - posibilidad atisbada en el caso de la iglesia holandesa y, de manera más difusa, en otras, al decir de este sector de la curia vaticana - propició un proceso de centralización, que parece no haber tocado techo $y$ que sigue dando alas a esta forma de gobiemo $y$ eclesiología en nuestros días. 